\title{
Yenikapı 27 Batığı: Gemi Elemanları, Yapım Tekniği ve Yapısal Özellikler*
}

\author{
Yenikapı 27 Shipwreck: Hull Members, Construction Technique and Structural Features
}

\section{Evren Türkmenoğlư* (1)}

\section{Öz}

Yenikapı (YK) 27 Batığı, 2004-2013 yılları arasında İstanbul Arkeoloji Müzeleri tarafından İstanbul/Yenikapı'da yürütülen kurtarma kazılarında açığa çıkarılmıştır. Bizans Döneminde Theodosius Limanı olduğu belirlenen kazı alanında bulunan 37 gemi kalıntısından biri olan YK27, büyük olasılıkla ticaret amacıyla kullanılan, MS 8-9. yüzyıllara tarihlenen bir yük gemisidir. Geminin ana yapı elemanlarından olan omurgası, karina kaplamaları ve döşeklerinin büyük bir kısmı sağlam vaziyette bulunmuş, su kesimi hattı üzerindeki kısmı ve diğer donanımları ise günümüze ulaşmamıştır. Bu çalışma kapsamında batığın mevcut ahşap yapı elemanları detaylı olarak incelenerek geminin yapım tekniği ve yapısal özellikleri aktarılmıştır. Bu özellikler, batığın çağdaşı olan diğer örneklerle karşılaştırmalı olarak ele alınarak Akdeniz gemi yapım geleneklerinin gelişim süreci bağlamında değerlendirilmiştir. Yenikapı 27 Batığının ahşap elemanlarının benzerlerine göre daha iyi korunmuş durumda olması, orta çağın erken dönemlerinde Akdeniz'de gemi geleneklerinde yaşanan önemli değişimlerin detaylarının daha iyi anlaşılmasına olanak sağlamaktadır. Geminin iskelet sistemini oluşturan postaların farklı dizilimi ve kaplamalarında kenar bağlantılarının bulunmaması, YK 27'nin antik gemi yapım geleneklerinden farklılaştığını gösteren başlıca özelliklerdir. Genel yapım özellikleri göz önüne alınarak geminin hem antik gelenekler hem de orta çağın erken dönemlerinde gelişmeye başlayan iskelet-ilk tekniğinin bir arada kullanıldığı özgün bir anlayışla inşa edildiği tespit edilmiştir.

\section{Anahtar Kelimeler}

Yenikapı, Theodosius Limanı, gemi arkeolojisi, Bizans, Akdeniz, gemi yapım gelenekleri

\begin{abstract}
Yenikapı (YK) 27 shipwreck was uncovered by salvage excavations conducted by the Istanbul Archaeology Museum between 2004 and 2013 at Yenikapı, Istanbul. The vessel, most probably a merchant ship from the 8th and 9th centuries $A D$, was one of the 37 boat remains found at the site where Thedosian Harbour was situated in the Byzantine period. The principal structural components of the ship's hull including the keel, bottom planks, and most of the floor timbers were found intact, however the upper structure above the waterline level and rigging are not survived. This study analyzes the construction technique and structural features of the vessel based on a detailed post-excavation examination of the wooden hull members; its construction features have been evaluated within the framework of development of shipbuilding traditions in the Mediterranean and by comparisons with other contemporaneous wrecks. As the condition of wreck's surviving hull members is exceptional, its examination provides a better understanding of important details
\end{abstract}

* Bu makale, İstanbul Üniversitesi, Sosyal Bilimler Enstitüsü Koruma, Yenileme ve Restorasyon Bilim Dalı'nda Prof. Dr. Ufuk Kocabaş danışmanlığında Evren Türkmenoğlu tarafından hazırlanmış olan “Yenikapı 27 Batığı: Konstrüksiyon Özellikleri ve Restitüsyon Önerisi" başlıklı doktora tezinden üretilmiştir.

** Sorumlu Yazar: Evren Türkmenoğlu (Dr. Öğr. Üyesi), İstanbul Üniversitesi, Edebiyat Fakültesi, Taşınabilir Kültür Varlıkları ve Onarımı Bölümü, İstanbul, Türkiye. E-posta: evrenturkmenoglu@gmail.com, ORCID: 0000-0002-5869-7360

Atıf: Turkmenoglu, Evren. "Yenikapı 27 Batğı: Gemi Elemanları, Yapım Tekniği Ve Yapısal Özellikler." Art-Sanat, 16(2021): 557-574. https://doi.org/10.26650/artsanat.2021.16.0019 
that might help to explain the profound change that occurred in Mediterranean shipbuilding during the early medieval period. Rarely seen framing pattern and non-edge fastened planking strakes are the major features that make YK 27 different from other ancient ship hulls. General characteristics of the ship suggest that it was built with a distinctive understanding of shipbuilding combined with ancient and early medieval traditions.

Keywords

Yenikapı, Theodosian Harbour, nautical archaeology, Byzantine, Mediterranean, shipbuilding traditions

\section{Extended Summary}

Salvage excavations by the Istanbul Archaeology Museum between 2004 and 2013 at Yenikap1, Istanbul, uncovered Theodosian Harbor, which was established in the late $4^{\text {th }}$ century AD. The harbor was one of the biggest in the capital in the Byzantine period, actively used at least until the $11^{\text {th }}-12^{\text {th }}$ century $A D$, when it was almost completely silted by the Lykos stream flowing into the harbor bay. The excavations revealed 37 boat remains dating from the $5^{\text {th }}$ to the $11^{\text {th }}$ centuries; some of which were considered derelict. At least three ships, with their final cargo still on board, sank in the harbor most likely due to a natural catastrophe.

Yenikap1 (YK27) was found near the eastern end of the site, approximately $2.7 \mathrm{~m}$ below the modern sea level. The surviving portion of the vessel covers an area of $13 \mathrm{~m}$ in length and $4 \mathrm{~m}$ in width. The wreck was documented and then systematically disassembled between November 2008 and May 2009 by a team of archaeologists, conservators, and technicians affiliated with Istanbul University's Division of Conservation of Marine Archaeological Objects. Waterlogged wooden hull members of the vessel have been stored in water tanks for the ongoing conservation and restoration procedures.

A small number of amphorae, amphora sherds, animal bones, fruit seeds, fragmented rope remains, and coins were found within the wreck context. Although associating those findings with the wreck is problematic due to heavy silting, some amphora sherds found immediately on the bottom planking might be considered as a part of the wrecks' final cargo.

Surviving hull members of the YK 27 include a keel made of 2 timbers, 45 planks forming 21 planking strakes, 47 extant and 23 dislocated frames, 5 stringers, 7 ceiling planks, 7 unidentified members, and 2 thick planks supporting the mast step. These supporting planks have been used as a reference for identifying the vessel's stem and stern sections. According to the usual location of a mast step at a location slightly forward of amidship, the western and eastern ends of the wreck were defined as the stem and the stern side, respectively. Species analysis indicates that the wooden hull members were sawn from at least nine different tree species. The general pattern suggests that the bottom planking and stringers are stone pine, the keel and floor timbers were made of different species of oak, and the futtocks are elm. Large distribution of those species in the Mediterranean limits the discussion on possible origins of the ship timbers used in the construction of YK 27. 
Almost all the floor timbers were fastened to the ship's keel with iron nails through predrilled round holes, which is an indicator of the purpose of building a sturdy skeletal structure. All planks were fastened to frames through iron nails driven from the outboard. The use of tree nails, a common practice in the ancient Mediterranean, was not recorded. The loose nail holes on the keel might suggest that molds or control frames were used during the erection of the frames and then removed after the completion of the skeletal structure. The consistent distance between holes and the locations of those (on both extremities and the middle) on the central timber with carpenter marks nearby the holes support this possibility.

The framing pattern of YK 27 was composed of long-armed floor timbers alternating to port, starboard, and futtocks. The futtocks were not scarved or nailed to floor timbers but were instead simply laid side by side, which possibly weakened the skeletal structure. Notably, the frame shapes are remarkably irregular and were not elaborately processed.

The planks were relatively thin and not fastened together through any edge fasteners such as mortise and tenons or edge dowels, which was a common ancient practice of shipbuilding in the ancient Mediterranean. The bottom planks were joined together with three planed scarves, while the butt joints were preferred above the third strake on the port side and the fourth strake on the starboard side. The residues of caulking were found in all seams.

The stringers nailed to floor timbers in the form of half logs -with one exceptionhad roughly flattened inboard surfaces and provided longitudinal skeletal support. In contrast, ceiling planks were not fastened to the floors and were only used when needed.

A possible construction sequence of the ship suggests that the frames or at least some frames of YK 27 were erected on the keel before installing the planks, thereby dictating the hull form. Non-edge fastened thin planks can also be an indication of the weak shell structure that did not remarkably contribute to the hull strength. However, the irregular frame shapes and floating futtocks are not ideal for a strong skeletal system. Therefore, general characteristics of YK 27 suggest that neither its skeleton nor its shell was significantly predominant in providing the hull strength. The ship appears to have been built with a distinctive understanding of shipbuilding combined with ancient and early medieval traditions.

An initial reconstruction study proposes that the ship's overall length was $17.2 \mathrm{~m}$ and the width was $4.1 \mathrm{~m}$. It was most likely a merchant ship with a maximum capacity of approximately 20 tons. 


\section{Giriş}

İstanbul'da Marmaray ve Metro raylı toplu ulaşım projelerinin inşa süreci kapsamındaki Yenikapı istasyonu şantiyesinde, 2004-2013 yılları arasında İstanbul Arkeoloji Müzeleri Müdürlüğü tarafından arkeolojik kurtarma kazıları gerçekleştirilmiştir. $58.000 \mathrm{~m}^{2}$ 'lik bir alanda yürütülen kazılarda Neolitik dönemden Osmanlı dönemi sonlarına kadar tarihlendirilen yaklaşık 65.000 envanterlik eser gün ışığına çıkarılmıştır. ${ }^{1}$ Buluntuların büyük bir kısmı ise Bizans dönemine aittir. Alanın MS 4. yüzy1l sonlarında Bizans imparatoru I. Theodosius adına inşa edilen ve zamanla Lykos (Bayrampaşa) deresinin taşıdığı alüvyonlu dolgu sebebiyle karaya katılarak işlevini yitiren Theodosius Limanı (Portus Theodosiacus) olduğu anlaşılmıştır. Liman dolgusu içinde MS 5-11. yüzyıllar arasına tarihlenen 37 gemi kalıntısı açığa çıkarılmıştır. Bu gemilerden en az üç tanesi (YK 1, YK 12, YK 35) kargo amforaları ile birlikte, diğer gemiler ise kargo ya da diğer donanımları olmaksızın bulunmuştur. Buna göre; gemilerin bir kısmının doğal bir afet sebebiyle liman içinde battıkları, diğerlerinin ise kullanım ömürlerini tamamlayarak liman içinde atıl durumda bırakılan gemiler olabilecekleri öne sürülmüştür².

\section{Yenikapı 27 Batı̆̆}

Yenikapı (YK) 27 numaralı batık kazı alanın doğu sınırına yakın konumda, yaklaşık 13 metre uzunluğunda ve 4 metre genişliğinde bir alana yayılmış vaziyette, günümüz deniz seviyesinin 2,70 metre altında açığa çıkarılmıştır (G. 1). Batık, İstanbul Üniversitesi, Sualtı Kültür Kalıntılarını Koruma Anabilim Dalı'na bağl1 ${ }^{3}$; arkeolog, konservatör, stajyer öğrenci ve teknisyenlerden oluşan arazi ekibi tarafından Kasım 2008 ve Mayıs 2009 tarihleri arasında detaylı şekilde belgelenmiştir. Belgeleme sürecini takiben gövdeyi oluşturan ahşap elemanları sistemli bir şekilde tek tek demonte edilerek araziden kaldırılmıştır. Suya doymuş vaziyetteki gemi elemanları ahşap ka-

1 Zeynep Kızıltan, "Marmaray-Metro Projeleri Kapsamında Yapılan Yenikapı, Sirkeci ve Üsküdar Kazıları," Istanbul Arkeoloji Müzeleri, I. Marmaray-Metro Kurtarma Kazıları Sempozyumu Bildiriler Kitabl 5-6 Mayıs 2008, ed. U. Kocabaş (İstanbul: Epsilon Yayınc1lık, 2010), 1-16.

2 Oya Algan vd. “Antik Theodosius Limanı'nın (Yenikapı) Jeo-Arkeolojisi,” İstanbul Arkeoloji Müzeleri, I. Marmaray-Metro Kurtarma Kazıları Sempozyumu Bildiriler Kitabı 5-6 Mayıs 2008, ed. U. Kocabaş (İstanbul: Epsilon Yayıncılık, 2010), 175-180; Doğan Perinçek, "Yenikapı Kazı Alanı'nın Son 800 Yıllık JeoArkeolojisi ve Doğal Afetlerin Jeolojik Kesitteki İzleri,” İstanbul Arkeoloji Müzeleri, I. Marmaray-Metro Kurtarma Kazıları Sempozyumu Bildiriler Kitabı 5-6 Mayıs 2008, ed. U. Kocabaş (İstanbul: Epsilon Yayınc1lık, 2010), 191-218; Cemal Pulak vd. "The Shipwrecks of Yenikapı and Their Contribution to the Study of Ship Construction," Stories from the Hidden Harbour: Shipwrecks of Yenikapı (Istanbul: Koç Üniversitesi Yayınları, 2013), 22-34; Cemal Pulak vd. "Eight Byzantine Shipwrecks from the Theodosian Harbour Excavations at Yenikapı in Istanbul, Turkey: an introduction," International Journal of Nautical Archaeology 44/1 (2015), 39-73; Ufuk Kocabaş, "İstanbul Üniversitesi Yenikapı Batıkları Projesi: Gemiler," İstanbul Arkeoloji Müzeleri, I. Marmaray-Metro Kurtarma Kazıları Sempozyumu Bildiriler Kitabı 5-6 Mayıs 2008, ed. U. Kocabaş (İstanbul: Epsilon Yayıncılık, 2010), 24-34; Ufuk Kocabaş, "The Yenikapı Byzantine-Era Shipwrecks, Istanbul, Turkey: A Preliminary Report and Inventory of the 27 Wrecks Studied by Istanbul University”, International Journal of Nautical Archaeology 44/1 (2015), 5-38.

3 İstanbul Üniversitesi Yenikapı Batıkları Projesi Prof. Dr. Ufuk Kocabaş başkanlığında devam etmektedir. 
salar içinde; kazı sonrası belgeleme, konservasyon ve restorasyon uygulamaları yapılmak üzere İstanbul Üniversitesi Yenikapı Batıkları Projesi Uygulama ve Araştırma Laboratuvarı'nda bulunan koruma havuzlarına taşınmıştır.

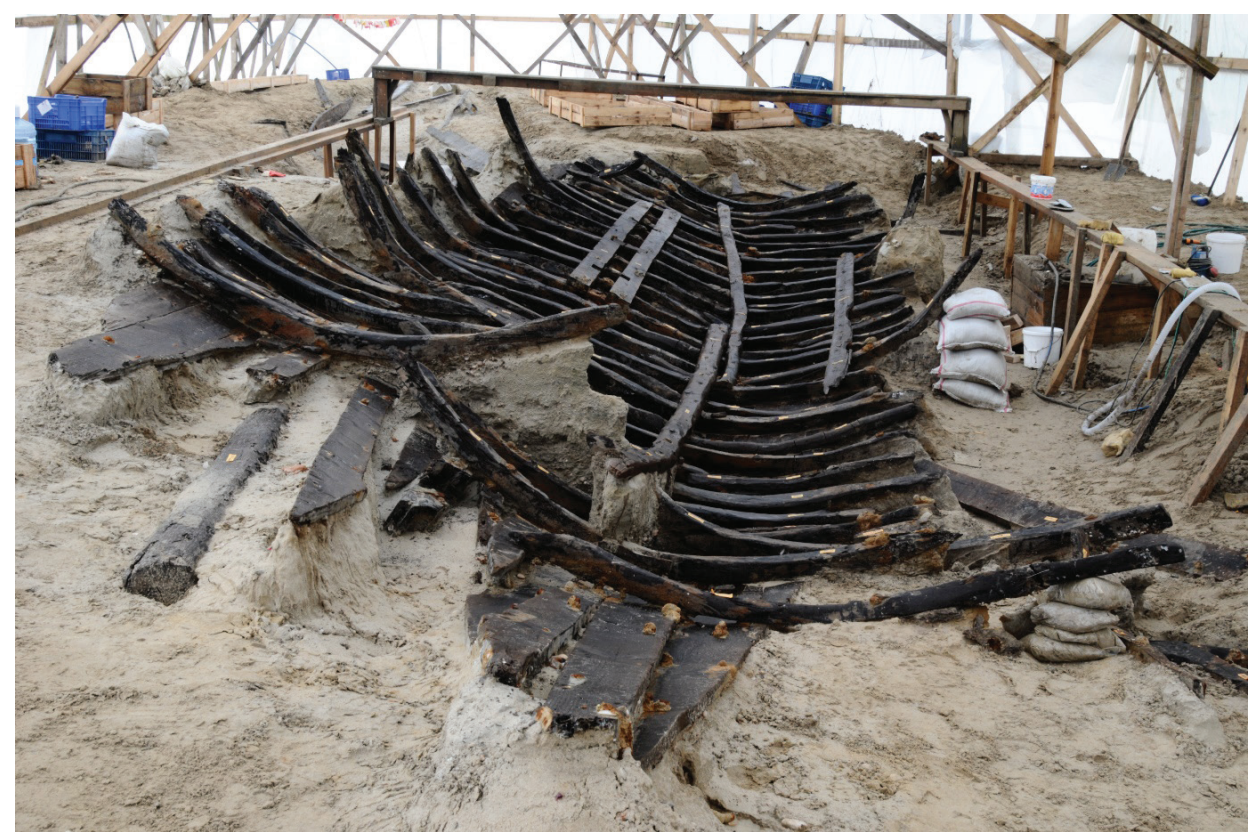

G. 1: Yenikap1 27 Batığının arazideki durumu (İstanbul Üniversitesi

Yenikapı Batıkları Projesi Arşivi)

YK 27 batığının mutlak tarihlenmesi için ahşap elemanlardan alınan 2 örnek üzerinde radyo-karbon ve 5 örnek üzerinde de dendrokronoloji analizleri yapılmıştır ${ }^{4}$. Analiz sonuçlarına göre batık MS 8-9. yüzyıllar arasına tarihlendirilebilmiştir. Özellikle daha güvenilir sonuçlar veren dendrokronoloji analizlerinde ağaç yaş halkalarının sınırlı sayıda olması nedeniyle tarihleme aralığının daraltılması mümkün olmamıştır.

Batık konteksti içinde az sayıda tüm amfora ve amfora parçaları, hayvan kemikleri, çeşitli meyve çekirdekleri, halat parçaları, kemik obje ve sikkeler bulunmuştur (G. 2). Ancak söz konusu buluntuların batıkla kesin olarak ilişkilendirilebilmesi tartışmalıdır. Buluntuların dalga ve akıntı gibi etkenlerle batık alanına sonradan taşınması, moloz ya da atık olarak dökülmüş olmaları ya da liman tabanının taraklanarak temizlenmesi sonucu tabandaki malzemenin yer değiştirerek birbirine karışmış olması gibi ihtimaller göz önüne alınmalıdır. Diğer yandan, bazı amfora parçalarının geminin içinde, karina kaplamalarının hemen üstünde bulunması, liman içinde batan gemiye ait kar-

4 Dendrokronoloji analizleri Arizona Üniversitesi Ahşap Halkası Araştırma Laboratuvarı uzmanlarından Dr. Tomasz Waszny ve İstanbul Üniversitesi-Cerrahpaşa, Orman Fakültesi öğretim üyesi Prof. Dr. Ünal Akkemik tarafından gerçekleştirilmiştir. Radyo-karbon analizleri, Oxford Üniversitesi Arkeoloji ve Sanat Tarihi Araştırma Laboratuvarı, Radyo-karbon Hızlandırma Birimi’nde (ORAU) yapılmıştır. 
gonun büyük bölümünün limanın görece sığ olmasından faydalanılarak kurtarıldığı, bir kısmının ise dolgu içinde kalmış olabileceğini akla getirmektedir (G. 2). Mevcut veriler, YK 27'nin doğal bir afet sonucu liman içinde batmış olan bir gemi kalıntısı ya da uzun yillar kullanıldıktan sonra limanda birakılan metruk bir gemi olup olmadığı konusunda kesin yargıya varılması için yeterli değildir. Bununla birlikte, her iki olasılıktan bağımsız olarak, geminin korunan kısmını oluşturan ahşap elemanlarda teredo navalis tahribatının görülmemesi geminin hızlı bir gömülmeye maruz kaldığını göstermektedir.

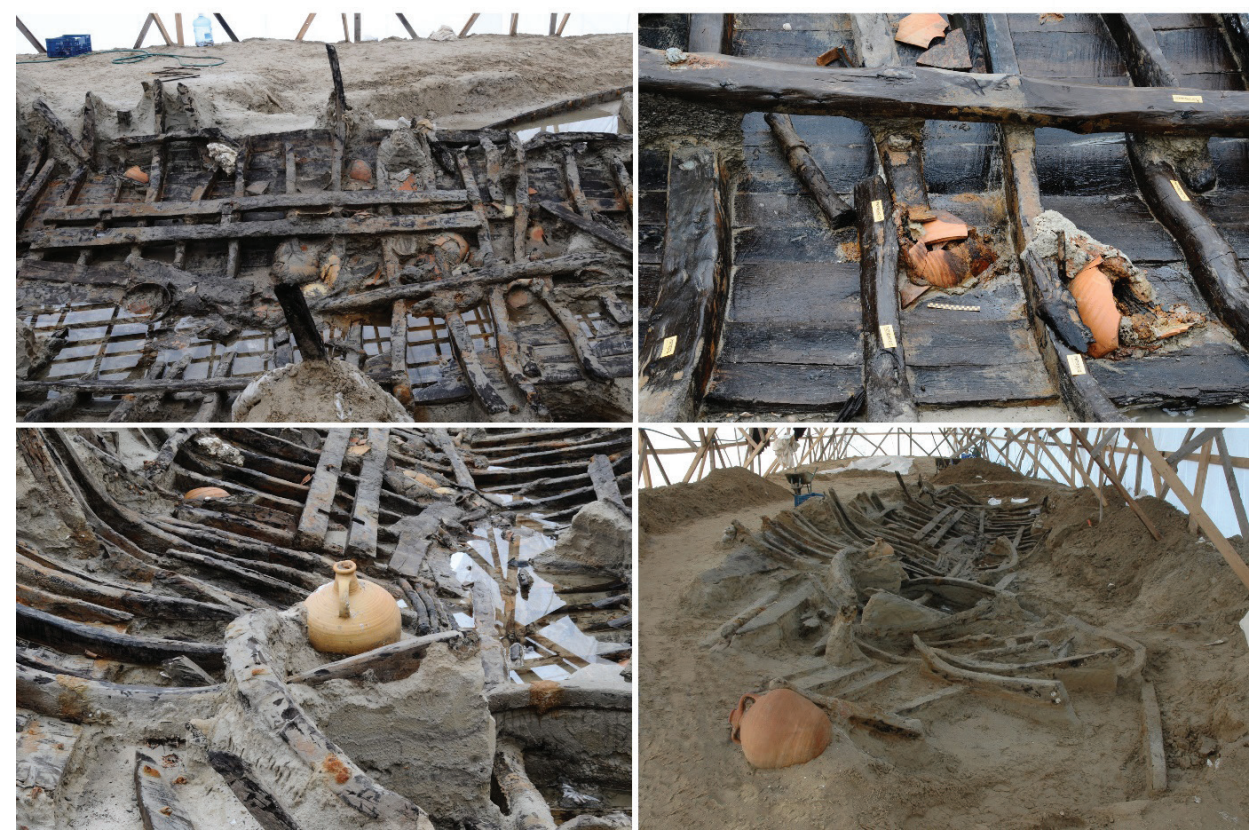

G. 2: Batık konteksti içinde yer alan arkeolojik dolgu. (İstanbul Üniversitesi Yenikapı Batıkları Projesi Arşivi)

\section{Gemi Elemanları}

Yenikapı 27 Batığının korunan ahşap elemanları 2 parça hâlinde omurga, 45 ayrı parçayı içeren 21 kaplama sırası, 47 in situ posta, 23 in situ vaziyette olmayan posta, 5 adet istralya, 7 farş tahtası, tanımlanamayan ahşap eleman (TP) olarak etiketlenen 7 parça ve 2 adet ıskaça desteğinden oluşmaktadır. Bu elemanlar genellikle geminin su hattı kesimi altında kalan karina kısmına aittir. Geminin yelken direği ve direğin oturtulduğu 1skaçayı taşıyan destek elemanlarının konumu referans alınarak batığın batı yönündeki ucu baş kısmı, yapısal bütünlüğü daha iyi durumdaki doğu ucu ise kıç kısmı olarak tanımlanmıştır (G. 3). 


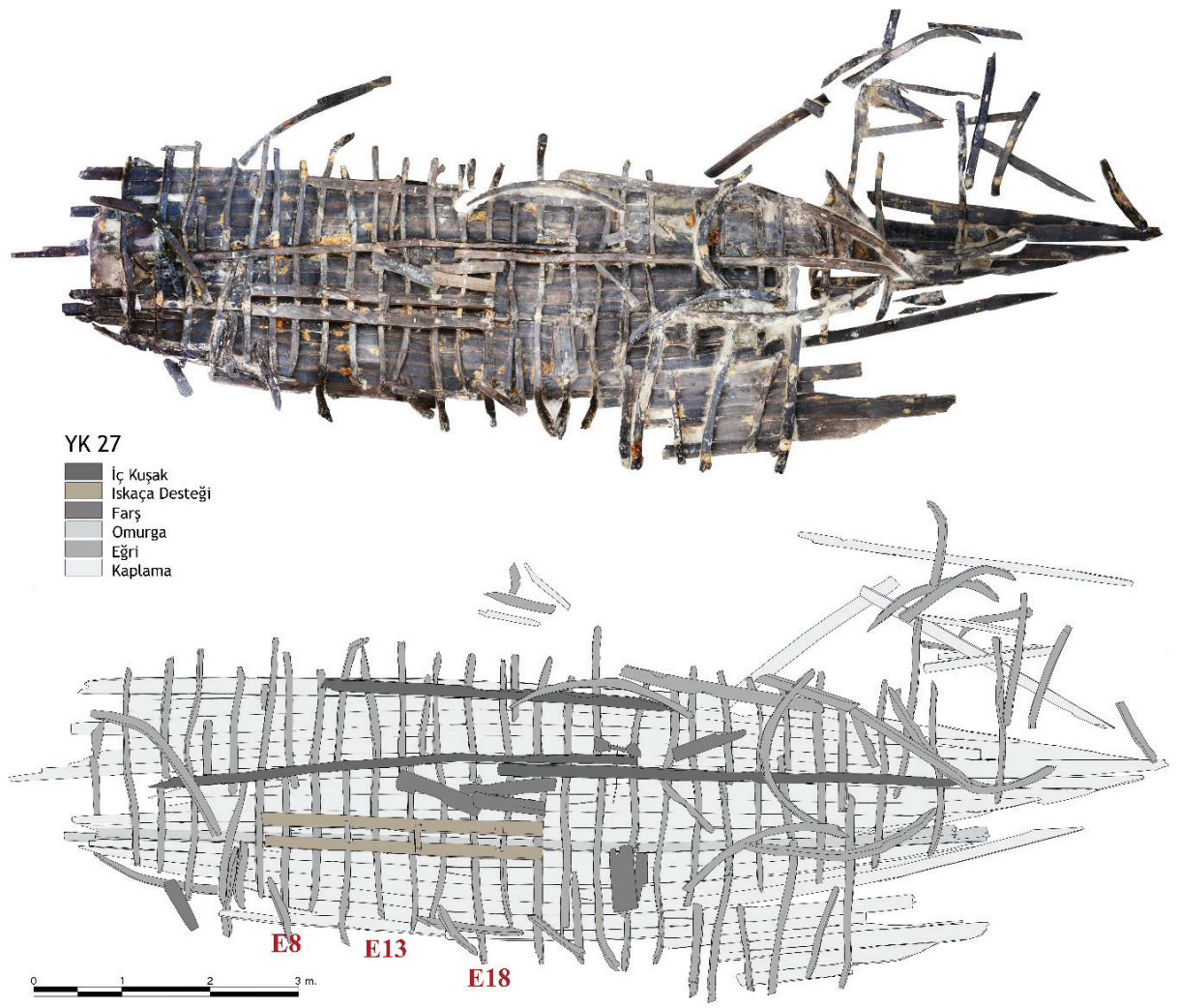

G. 3: Gemi elemanları: fotomozaik (üst) ve plan (alt). (İstanbul Üniversitesi Yenikapı Batıkları Projesi Arşivi)

Geminin baş ve kıç bodoslamaları, borda kaplamaları, küpeşte, güverte, kemereler, yumrular ve yelken donanımı gibi çoğunluğu su kesimi hattı üzerinde yer alan yapı elemanları günümüze ulaşmamıştır. Mevcut gemi elemanlarının hangi ağaçlardan elde edildikleri tüm parçalardan alınan 140 örneğin cins-tür analizleriyle belirlenmiştir ${ }^{5}$. Analizler, geminin yapımında fistıkçamı, kızılçam, herdem yeşil meşe, kırmızı meşe, akmeşe, karaağaç, Akdeniz servisi, kavak ve kayın olmak üzere 9 farklı cins/türe ait ağaç kullanıldığını göstermektedir (G. 4). Çeşitli istisnalar haricinde genel olarak dış kaplamalar ve istralyaların yapımında başlıca tür olarak fıstık çamı, döşekler ve omurgada meşe, posta üstü parçalarda ise karaağaç kullanıldığ tespit edilmiştir ${ }^{6}$. Bu ağaç cinsleri hem Anadolu'da, hem de Akdeniz havzasının birçok bölgesinde yaygın biçimde yetişmektedir. Bu sebeple, Yenikapı 27 batığı ahşap elemanlarının cins-tür

5 Cins-tür analizleri İstanbul Üniversitesi-Cerrahpaşa, Orman Fakültesi öğretim üyesi Prof. Dr. Ünal Akkemik tarafindan gerçekleştirilmiştir.

6 Ünal Akkemik, Yenikapı Batıkları Cilt II: Yenikapı Batıklarının Ahşapları (İstanbul: Ege Yayınları, 2015), 99. 
analiz sonuçlarına göre geminin yapıldığı ya da yapımında kullanılan ağaçların getirildiği bölge kesin olarak belirlenememiştir.

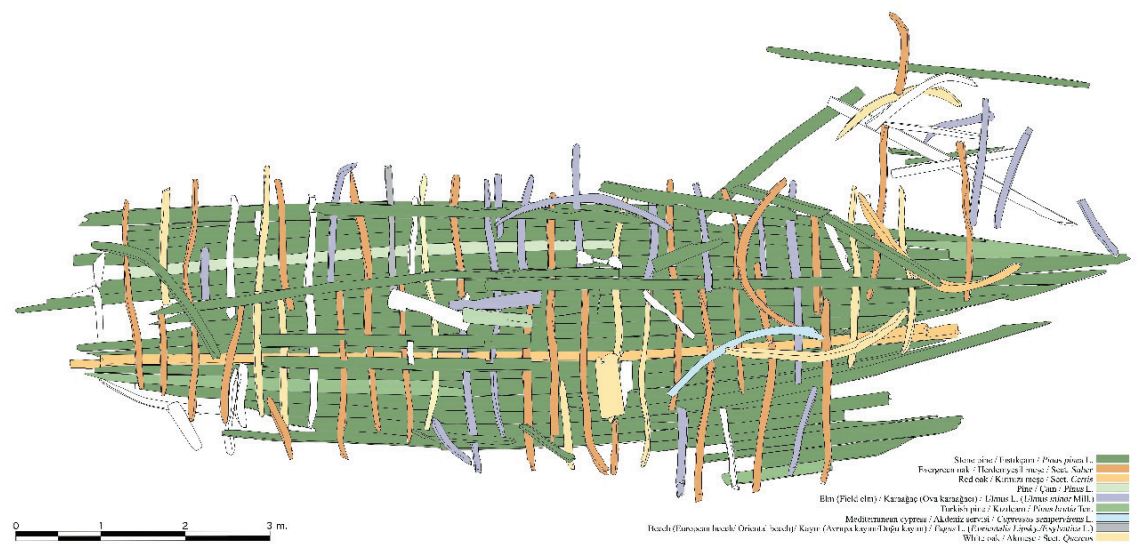

G. 4: Gemi elemanlarının cins-türleri (Akkemik, Yenikapı Batıkları Cilt II: Yenikapı Batıklarının Ahşapları, 99)

Gemi inşasında kullanılan tüm ahşap elemanlar üzerinde Akdeniz geleneğine uygun olarak yoğun testere izleri görülmektedir. Özellikle kaplama tahtalarının tüm yüzeyleri boyunca görülebilen bu izler kaplamaların ağaç tomruklarından muhtemelen kol hızarı ile biçilerek işlendiğine işaret etmektedir. Bu yöntem orta çağ ikonografisinde de temsil edilmiş ve yakın tarihe kadar Anadolu'da geleneksel olarak kullanılmıştır. Testere izlerinin yanı sıra tüm gemi elemanlarındaki izlerden balta ya da keser kullanılarak yüzeylerin yer yer tesviye edildiği de anlaşılmaktadır.

\section{Omurga}

Batığın omurgası birbirine kamalı kademeli geçme ile birleşen, toplam 10,37 metre uzunluğunda, ortalama $27 \mathrm{~cm}$ derinliğinde ve $12 \mathrm{~cm}$ genişliğindeki iki ayrı parçadan (OM-1 ve OM-2) oluşmaktadır (G. 5). Omurganın derinliğinin genişliğinden oldukça fazla olması geminin ağırlık merkezini aşağıya çekerek geminin dengesine katkı sağlamıştır. Omurganın her iki ucu, geçmeleri ve özellikle üst yüzeyi oldukça iyi korunmuştur. Ana omurga olarak tanımlanan, 6,78 metre uzunluğundaki OM-1 baş ve kıç yönlerine doğru hafif kavisli, 3,96 metre uzunluğundaki OM-2 ise geminin kıç kısmında oldukça belirgin bir kavis yaparak yükselmektedir ${ }^{7}$. Omurganın her iki parçasında da üst yüzeylerin her iki yanında, yaklaşık $4 \mathrm{~cm}$ aşağıdan başlayan aşoz bulunmaktadır. Aşoz boyunca düzensiz mesafelerle bulunan 39 metal çivi deliği burma tahtalarının aşoz içine oturtularak omurgaya çivilendiğini göstermektedir. Omurga üst yüzeyinde ise 38 çivi deliği tespit edilmiştir. Bunlardan üçü; omurga parçalarını birbirine ve bodoslamalara

7 Ölçülere geçmeler de ayrı ayrı dâhil edilmiştir. Birleşmiş vaziyetteki uzunluk ise 10.37 metredir. 
bağlayan kamalı kademeli geçmeleri sağlamlaştıran çivilere aittir. Diğerlerinin büyük bölümü ise omurgayı döşeklere bağlayan ya doğrudan ya da matkapla açılmış 1-1,5 cm çapındaki yuvarlak formlu deliklerden geçen demir çivilere aittir. Döşekler ve omurga üzerindeki çivi deliklerinin eşleştirilmesi sonucunda ise toplam 7 çivi deliğinin döşekler üzerinde karşılığ1 olmadığ1 anlaşılmıştır. Boşta bulunan bu çivilerden üçünün (E8, E13 ve E18 numaralı döşeklerin yer aldığı istasyonlarda) hemen yan kısımlarında marangoz işaretleri olması muhtemel izlere de rastlanmıştır (G. 3).
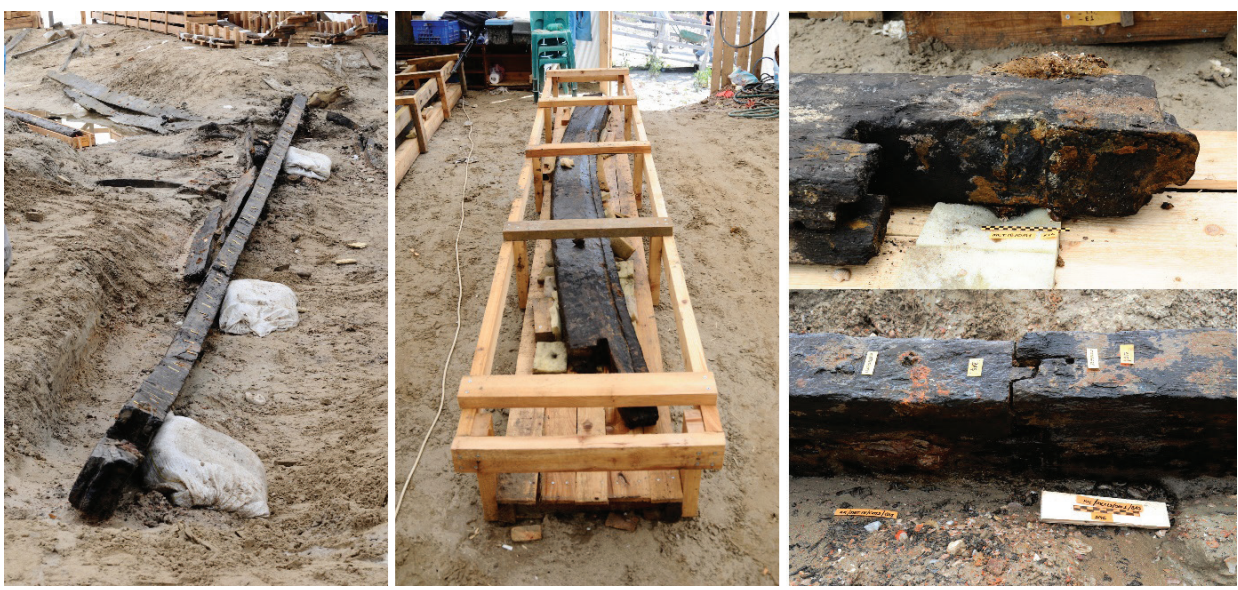

G. 5: Omurga ve omurga birleşmeleri (İstanbul Üniversitesi Yenikapı Batıkları Projesi Arşivi)

\section{Kaplama Tahtaları}

Batığın sancak tarafında 11 ve iskele tarafında 11 olmak üzere toplam 22 kaplama sırası tanımlanmıştır. Kaplama sıralarını oluşturan toplam 45 parça in situ kaplama tahtasının tamamı geminin karina kısmına ait olup orijinal kenar ve yüzeyleri oldukça iyi korunmuş durumdadır. Kaplamaların kalınlıkları 1,3-4,5 cm arasında, genişlikleri 6,4 cm-22,7 cm, uzunlukları ise 2,24-6,74 metre arasında değişmektedir. Armuz kaplama yöntemiyle inşa edilen kaplama sıralarının oluşturulmasında üç kenarlı parile ya da sokra tipinde birleşmeler kullanılmıştır. Genellikle iki, bazen de üç posta istasyonunu kaplayacak uzunlukta yapılan parileler arasında herhangi bir bağlantı elemanına rastlanmamıştır (G. 6).
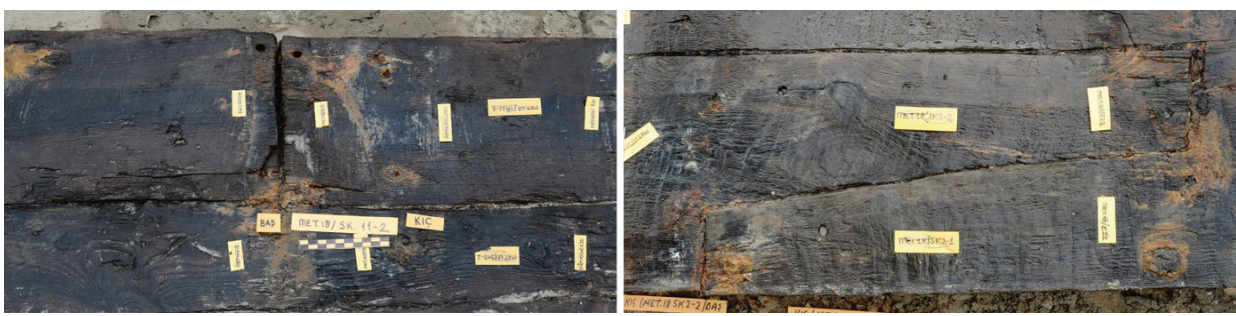

G. 6: Kaplama sıralarındaki sokra birleşme (sol) ve üç kenarlı parile (sağ)

(İstanbul Üniversitesi Yenikapı Batıkları Projesi Arşivi) 
Geminin iskele tarafında ilk üç, sancak tarafında ise ilk 4 sıra kaplamada sadece 3 kenarlı parileler kullanılmış, bu seviyeden sonra yer yer sokralar tercih edilmiştir. Kaplamaların hiçbirinde kavela-zıvana, kama-zıvana vb. kenar bağlantı elemanı bulunmamaktadır. Bu özelliğiyle YK 27 Batığ1, Yenikapı 10, 17, 19, 29, 31 numaralı batıklarla beraber Yenikapı'da açığa çıkarılan diğer 30 batıktan ayrılmaktadır ${ }^{8}$. Aynı duruma Agay A, Bataiguier, Port Berteau 2, Tantura B, Tantura E, Tantura F, Serçe Limanı batıklarında da rastlanmaktadır'. Kaplamalar sadece, ortalama 0,5 cm kenar uzunluğuna sahip dörtgen kesitli demir çivilerle postalara dıştan raptedilmiştir. Tüm kaplama tahtalarının armuzlarında kalafat kalıntıları tespit edilmiştir. İçeriği tam olarak tanımlanamayan kalafat kalıntılarının bir çeşit reçine ya da katranın çeşitli bitki lifleri ve hayvan kıllarının karışımı ile hazırlanmış olması muhtemeldir.

\section{Postalar}

Geminin iskeletini oluşturan postalardan $51^{\prime}$ i orijinal konumlarında bulunmuştur. Bunlardan 26'sı döşek ve 25'i posta üstü parçaları olarak tanımlanmıştır. 24 posta ise dağınık vaziyettedir. Postaların büyük çoğunluğunun orijinal yüzey, kenar ve uçları iyi korunmuştur. Ancak formları oldukça düzensiz olan postaların, aynı parçalarda dahi kalınlık ve genişliklerinin dikkat çekici ölçüde değişkenlik gösterdiği gözlenmiştir. Buna göre postaların elde edilmesinde doğal ağaç dallarının kıvrımlarından yararlanılarak özenli bir kesim yapılmadığı anlaşılmıştır. Bu durum, bazı postalar üzerinde hâlen ağaç kabuklarının bulunmasıyla da doğrulanmaktadır. Postalar genel olarak sintine dönüşüne denk gelen noktalarda daha kalın, uç kısımlara doğru ise daralmakta, kaplamalara oturan yüzeylerin kenarları düzgün, üst yüzeyleri ise pahlıdır. Postalar birbirini izleyen döşek ve posta üstü sıraları hâlinde dizilmiştir. Döşekler geminin karina kısmına şekil verirken posta üstü parçalar iskeleti tamamlayarak küpeşteye uzanmaktadır. YK 27 batı̆̆ı döşekleri geminin tabanını enlemesine kaplayan ve tek kolu uzun olup sintine dönüşünde kıvrım yaparak bordaya doğru uzanan "L" biçimli parçalardan ibarettir. Döşeklerin uzun kolu sırasıyla bir istasyonda sancak bordaya, bir

8 Kocabaş, "The Yenikapı Byzantine-Era Shipwrecks, Istanbul, Turkey: A Preliminary Report and Inventory of the 27 Wrecks Studied by Istanbul University,” 5-38; Işıl Özsait Kocabaş, "The Yenikapı 12 Shipwreck, a 9th-Century Merchantman from the Theodosian Harbour in Istanbul, Turkey: Construction and Reconstruction," International Journal of Nautical Archaeology 47/2 (2018), 357-390; Pulak vd. "Eight Byzantine Shipwrecks from the Theodosian Harbour Excavations at Yenikapı in Istanbul, Turkey: an introduction," 39-73.

9 Patrice Pomey, Yaacov Kahanov ve Eric Rieth, "Transition from Shell to Skeleton in Ancient Mediterranean Ship-Construction: Analysis, Problems and Future Research," International Journal of Nautical Archaeology 41/2 (2012), 235-314; Yaacov Kahanov, Y., J. Royal ve J. Hall, "The Tantura Wrecks and Ancient Mediterranean Shipbuilding," The Philosophy of Shipbuilding, ed. F. M. Hocker, C. A. Ward (College Station: Texas A\&M University Press, 2004), 113-127; Yaacov Kahanov vd., "Dor Underwater Excavation, Report of the 2008 Season," Recanati Institute for Maritime Studies News 34 (2008), 16-18; Ofra Barkai ve Yaacov Kahanov, "The Tantura F Shipwreck, Israel," International Journal of Nautical Archaeology 36/1 (2007), 21-31; Sheila Matthews ve Richard Steffy, "The Hull Remains," Serçe Limant, An Eleventh- Century Shipwreck, Volume 1: The Ship and Its Anchorage, Crew, and Passengers, ed. G.F. Bass vd. (College Station: Texas A\&M University Press, 2004), 81-122. 
sonraki istasyonda ise tersi istikamette olan iskele bordaya uzanacak şekilde sırayla dizilirken aralara posta üstü parçalar yerleştirilmiştir.

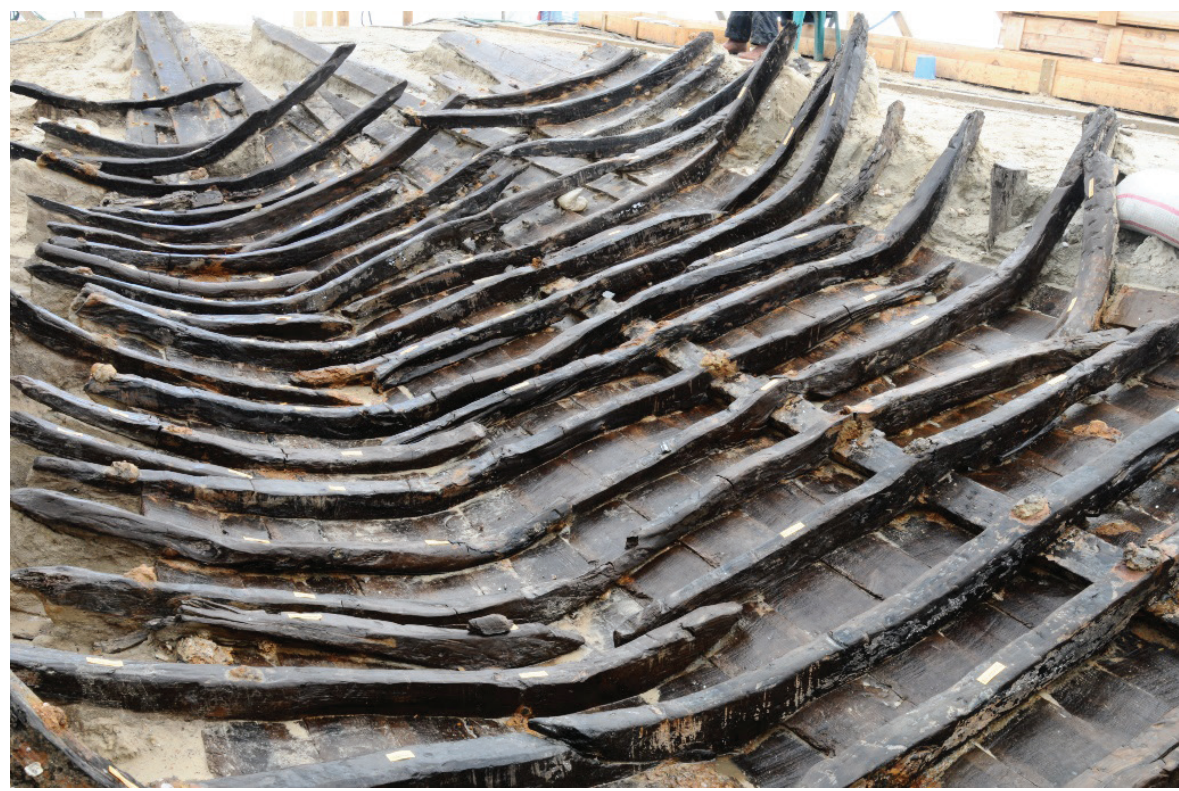

G. 7: Postaların dizilimi (İstanbul Üniversitesi Yenikapı Batıkları Projesi Arşivi

$\mathrm{Bu}$ sisteme en yakın örnekler Bataiguier ve Serçe Limanı batıklarında görülmektedir $^{10}$. Döşekler arasındaki mesafe omurga üzerinde merkezden merkeze $32 \mathrm{~cm}-40$ $\mathrm{cm}$ arasında değişmektedir. İskelet oluşturulurken döşek ve posta üstü parçalar birbirlerine herhangi bir geçme veya bağlantı elemanıyla birleşmemektedir. Döşek ve posta üstü parçaların uç kısımları genellikle yan yana gelecek şekilde düzenlenmiştir. Döşekler, çiviler çakılmadan önce açılmış, 1-2 cm çapındaki yuvarlak deliklerden geçen yaklaşık 12-15 cm uzunluğundaki dörtgen kesitli demir çiviler ile omurgaya sabitlenmiştir. Hemen hemen tüm döşeklerin omurgaya demir çivilerle sabitlenmiş olması iskelet sisteminin sağlamlığına özellikle önem verildiğine işaret eder. Postaların alt yüzeylerinde ise kaplama-posta bağlantısını sağlayan ortalama 0,5 cm kenar uzunluğuna sahip, dörtgen formlu çok sayıda çivi deliği bulunmaktadır. Bu durum kaplamaların döşek ve posta üstü parçaların üst yüzeylerine ulaşmayan, yaklaşık 7-10 cm uzunluğunda demir çivilerle dışarıdan bağlandığını göstermektedir. Tüm döşeklerde omurgaya oturan yüzeyin her iki kenarına açılmış, üçgen biçimli birer sintine deliği de bulunmaktadır.

10 Pomey, Kahanov ve Rieth, "Transition from Shell to Skeleton in Ancient Mediterranean Ship-Construction: Analysis, Problems and Future Research," 235-314; Richard Steffy, "Construction and Analysis of the Vessel," Serçe Limani, An Eleventh- Century Shipwreck, Volume 1: The Ship and Its Anchorage, Crew, and Passengers, ed. George F. Bass vd. (College Station: Texas A\&M University Press, 2004), 153-171. 


\section{İstralyalar}

YK 27 batığı ahşap elemanları arasında geminin iç kısmında postalara demir çivilerle bağlanarak iskeleti güçlendiren 5 adet istralya yer almaktadır. Korunan yüzeyleri iyi tanımlanabilir durumda olan parçaların uzunlukları yaklaşık 2,3-5,5 metre, kalınlıkları 3,3-6,1 cm, genişlikleri ise 6,4-15,7 cm arasında değişmektedir. Kalın bir kaplama tahtasını andıran biri hariç (İÇK-3) diğer hepsinin kesitleri yarım tomruk biçimine oldukça yakın ancak üst yüzeyleri kabaca düzleştirilmiştir.

\section{Farș Tahtaları}

Batık içinde herhangi bir diğer gemi elemanına bağlı olmayan 7 adet farş tahtası tanımlanmıştır. Orijinal yüzey ve kenarları korunan farşların uzunlukları 82-99 cm, genişlikleri 15-21 cm, kalınlıkları ise 1,6-3 cm arasında değişmektedir. Farş tahtaları üzerinde çivi vb. bağlantı elemanlarına rastlanmamıştır. Bu sebeple tahtaların herhangi bir yere sabitlenmediği ve seyyar olarak sadece gerektiği zaman kullanıldıkları tahmin edilmektedir.

\section{Iskaça Desteği}

Batığın yelken donanımına ilişkin bulunan yegâne kanıt ıskaçanın üzerine oturtulduğu destek parçalarıdır. Bu parçalar, 3,18 metre (TP4) ve 3.13 metre (TP5) uzunluğunda, döşeklerin üzerine yerleştirilmiş kalın birer kaplama tahtası formundadır. Parçaların kalınlıkları 3,7-6,4 cm arasında, genişlikleri 12,5 ve 15,6 cm arasında değişmektedir. Destek parçaları karşılıklı olarak aralarında yaklaşık $14 \mathrm{~cm}$ mesafe kalacak şekilde 10 döşek üzerine yerleştirilip döşeklere matkapla açılmış deliklerden geçirilen metal çivilerle bağlanmıştır. Destek parçalarının karşı1lıklı yüzlerine açılmış üçer adet girinti mevcuttur. Ortalama $8 \times 7 \mathrm{~cm}$ ölçülerindeki bu girintilerin derinlikleri 1,8 ile 2,5 cm arasında değişmektedir. TP4 ve TP5'in karşılıklı kenarlarındaki bu girintilere enlemesine oturan iki parçadan sadece biri korunmuştur. Parça $27 \mathrm{~cm}$ uzunluğunda, $7 \mathrm{~cm}$ genişliğindedir. Günümüze ulaşmayan 1skaça büyük olasılıkla T kesitli olup alt yüzeyinde bulunan girintiler vasıtasıyla destek parçalarının orta kısmına oturulmuş olmalıdır (G. 8). Buna göre TP4 ve TP5 1skaçaya destek olurken aralarına karşılıklı yerleştirilen tahtalar kilit vazifesi görerek 1skaçanın öne ve arkaya hareketini engellemektedir. 

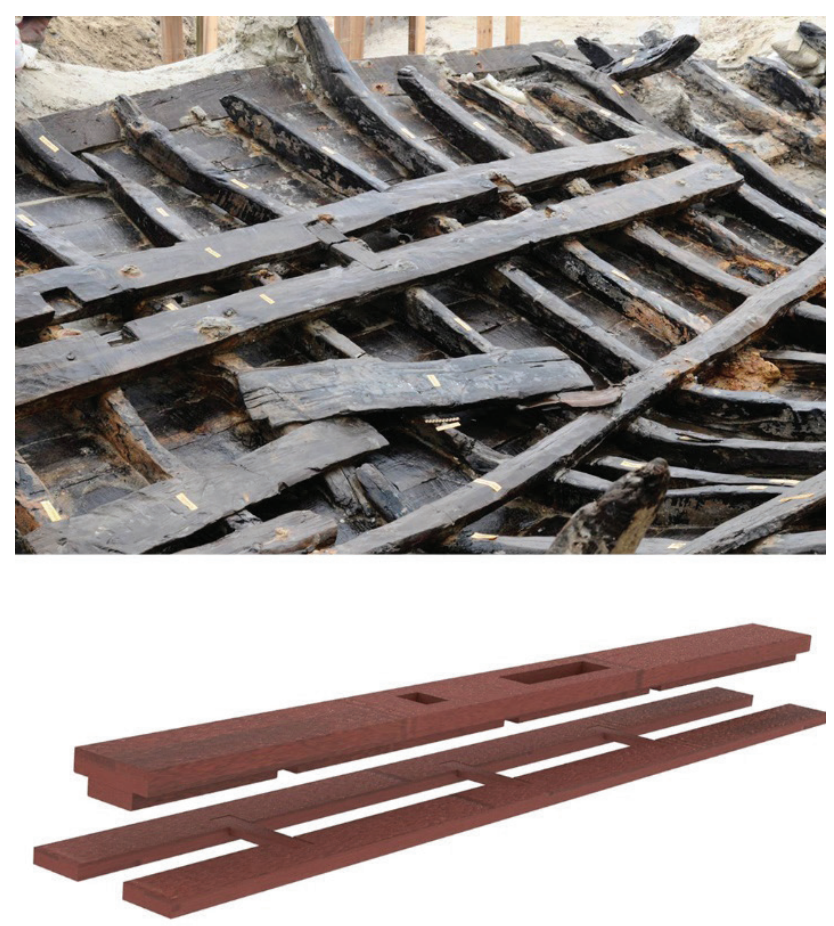

G. 8: Iskaça desteği ve 1skaçanın restitüsyonu (İstanbul Üniversitesi Yenikapı Batıkları Projesi Arşivi

\section{Batığın Restitüsyonu}

YK27 Batığının restitüsyonun yapılması için bütün gemi elemanlarının digitizer cihaz1 ile çizimleri yapılmış, bu çizimler dijital ortamda katı modele dönüştürülmüş, aynı zamanda fiziki modeli de 3 boyutlu yazıcı yardımıyla elde edilmiştir. Batığın bütüncül durumdaki tüm posta istasyonlarından en kesitler alınmış, boyuna kesitler için ise daha iyi durumdaki sancak kısmı referans olarak kullanılmıştır. Arkeolojik gemilerin restitüsyonlarında yaygın olarak kullanılan bir yöntem olan sancak ve iskele kısımlarının simetrik olduğu varsayımı ile eksik kısımlar tamamlanmıştır. Steffy ${ }^{11}$, gemilerin sancak ve iskele kısımlarının tam simetrik olmadığını ancak korunan tarafın korunmayan taraf için referans alınabileceğini dolayısıyla bu varsayımın geçerli olarak kabul edilebileceğini belirtmiştir. Geminin korunmayan üst yapısı, baş ve kıç bodoslamaları, yelken donanımı gibi özellikleri mevcut kaplamaların dönüş açıları, mevcut döşeklerin en kesitlerindeki gövde altı açılarının karşılaştırılması, geminin çağdaşı olan arkeolojik batıkların boyutları ve daha önce yapılan restitüsyon çalışmaları, son olarak da orta çă̆ ikonografisindeki gemi tasvirleri göz önüne alınarak hipotetik olarak tamamlanmıştır

11 Richard Steffy, Wooden Shipbuilding and the Interpretation of Shipwrecks (College Station: Texas A\&M University Press, 1994), 15. 


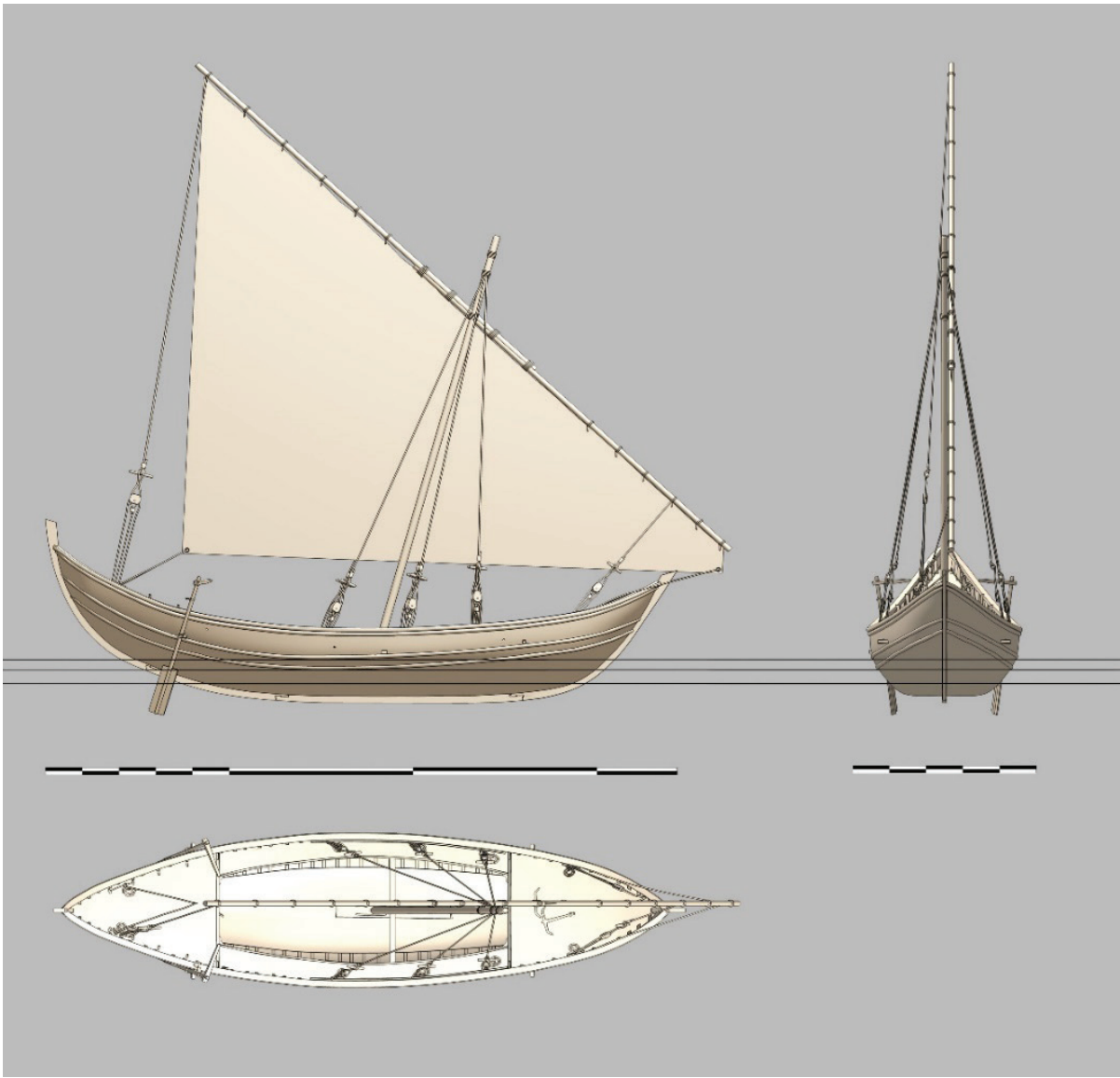

G.9: YK 27 Batığı restitüsyonu (İstanbul Üniversitesi Yenikap1

Batıkları Projesi Arşivi-Model: Tayfun Öner)

Restitüsyon çalışmalarına göre geminin tam boyunun 17,2 metre, azami genişliğinin 4,1 metre olabileceği önerilmiştir. Boş durumdayken deplasmanı 5,5 ton olarak hesaplanan geminin tam kapasite ile yaklaşık 20 ton kargo taşıyabileceği hesaplanmıştır. Yapısal özellikleri batığın ticaret amacıyla kullanılan bir yük gemisine ait olabileceğini göstermektedir.

\section{Değerlendirme}

Yenikapı 27 batığı öncelikle mevcut ahşap elemanlarının bütüncül durumda bulunarak, karina kısmı ve sintine dönüşlerindeki gövde açılarının iyi korunmaları sebebiyle Akdeniz'de kazı çalışmaları tamamlanmış batıkların birçoğuna oranla yapım teknolojisi ve yapısal özelliklere ilişkin daha güvenilir veriler sunmaktadır. Örneğin, benzerleri arasındaki Serçe Limanı batığında sadece bir döşeğin sintine dönüşündeki 
orijinal açısı korunmuştur ${ }^{12}$. Tantura Lagünü batıkları ise iyi korunmuş olmalarına rağmen ya kısmen incelenebilmiş ya da kazı alanından kaldırılmayarak sadece su altında, demonte edilmeden belgelenebilmişlerdir ${ }^{13}$.

Yenikapı 27 Batığ 1 gemi elemanlarının detaylı olarak incelenebilmesi yapım teknolojisinin de daha iyi anlaşılmasını sağlamıştır. Bunlar arasında en dikkat çekici özelliklerden biri batığın kaplamaları arasında herhangi bir bağlantı elemanı bulunmamasıdır. Genellikle, kaplamaların iskeleti oluşturan postalardan önce birbirlerine kenar bağlantılarıyla kenetlenerek inşa edildiği kabuk tekniği ile özdeşleştirilen kaplama kenar bağlantıları MS 1. bin ortalarına kadar Akdeniz'de yaygın olarak kullanılmış$\operatorname{tır}^{14}$. Bu dönemden sonra kavela-zıvana ya da kama zıvana gibi bağlantı elemanlarının kullanımının giderek azalmaya başladığı, boyutlarının küçülüp, aralarındaki mesafelerin artarak daha seyrek yerleştirildikleri görülmektedir. Bu durumun gemi yapım geleneklerinde kabuk sisteminden, postaların kaplamalardan önce yapıya eklendiği iskelet sistemine geçişe işaret ettiği öne sürülmüştür ${ }^{15}$. Ancak özellikle ortaçağın erken dönemlerinde gemi yapım tekniklerinin çeşitlenmesi ve karmaşıklaşması sadece kenar bağlantılarının kullanımına dayanarak gemi yapım yönteminin açıklanmasını zorlaştırmaktadır. Yenikapı 27 Batığının iskeleti de kaplamalara benzer şekilde antik dönemde kullanılan teknikten farklılaşmaktadır. İskeleti oluşturan ana elemanlar olan postaların dizilim düzeni Akdeniz'de şimdiye kadar bulunan batıklarda yaygın olarak kullanılmamıştır. Yaygın olarak kullanılan düzen, Klasik çağlardan itibaren sıklıkla görülen birbirini takip eden döşek, yarım döşek ve posta üstü sıralarından oluşmaktadır $^{16}$. YK 27'de ise düzenli aralıklarla tek kolu uzun döşeklerin diğer kolda bordaya uzanan posta üstü parçalarla oluşturduğu kombinasyon tercih edilmiştir. Döşek ve posta üstü parçaların birbirine bağlı olmayıp yan yana yapıya yerleştirilmesinin ise bu parçaların yapıya uzunlamasına destek veren istralyalara sabitlenmelerine rağmen iskeletin yapısal kuvvetini zayıflattı̆̆ı söylenebilir.

Geminin yapım aşamalarıyla ilgili önemli ipuçlarını batığın omurgasına ait bulgular vermektedir. Geminin neredeyse tüm döşekleri omurgaya demir çivilerle sabitlenmiş olup bu çivilere ait deliklere omurga üzerinde ve karşılıklarına döşeklerde

12 Matthews ve Steffy, "The Hull Remains," 81-122; Richard Steffy, "The Reconstruction of the 11th century Serçe Liman Vessel: A Preliminary Report,” International Journal of Nautical Archaeology 11/1 (1982), 13-34.

13 Hadas Mor, “The Dor 2001/1 Shipwreck-Hull Construction Report," Transferts Technologiques en Architecture Navale Méditerraneenne de L'Antiquité aux temps Modernes: Identité Technique et Identité Culturelle, ed. P. Pomey (Paris: Institut Français D’etudes Anatoliennes Georges-Dumezil, 2010), 87-96; Pulak vd. "Eight Byzantine Shipwrecks from the Theodosian Harbour Excavations at Yenikap1 in Istanbul, Turkey: an introduction," 39-73.

14 Steffy, Wooden Shipbuilding and the Interpretation of Shipwrecks, 83-85.

15 Pomey, Kahanov ve Rieth, "Transition from Shell to Skeleton in Ancient Mediterranean Ship-Construction: Analysis, Problems and Future Research," 235-314.

16 Steffy, Wooden Shipbuilding and the Interpretation of Shipwrecks, 23-78; Steffy, "Construction and Analysis of the Vessel," 158. 
rastlanmıştır. Ancak omurga üzerinde düzenli sayılabilecek aralıklarla ana omurganın başında, ortasında ve sonunda yer alan boşta çivi delikleri de tespit edilmiştir. $\mathrm{Bu}$ delikler daha önce bu konumlarda bulunan ancak daha sonra tamir amaçlı sökülen döşeklere ait olabilecekleri gibi, geminin inşası sırasında gövde formunu belirleyen kalıp veya kontrol postalarına da ait olabilirler. Boşta bulunan bu çivi deliklerinin hemen yanlarına kazınan ve marangoz işareti olabileceği değerlendirilen işaretlerin varlığı ikinci olasılığı güçlendirmektedir. Bu teknikle inşa edilen gemilerde iskeleti oluşturan postaların bir kısmı, genellikle de baş ve kıç kısımlara yakın olan ve geminin vasatına konumlandırılan postalar omurgaya yerleştirilir ve kaplamalar postalara daha sonradan bağlanır. Bu aşamadan sonra tekne formunu belirleyen kalıp postaları başka gemilerde kullanılmak üzere sökülebilir ya da yerinde bırakılabilir ${ }^{17}$. Gemi arkeolojisi literatüründe gemi inşasında kalıp veya kontrol postaları, tiriz ya da yalancı formaların kullanılıp kullanılmadığı sıklıkla tartışılmıştır. Etnografik kanıtlar, bu olasılığın göz ardı edilmemesi gerektiğini göstermektedir. Ancak kalıp ya da tirizler, kullanıldıktan sonra genellikle yapıdan söküldükleri için bu tekniğin antik dönemde ya da ortaçağda kullanıldığını kanıtlayabilecek arkeolojik kanıtların elde edilmesinin oldukça zor olduğu ifade edilmiştir ${ }^{18}$. Yenikap1 27 Batığ 1 omurgasında bulunan boşta çivi deliklerinin bu tekniğin kullanıldığına dair nadir rastlanan arkeolojik kanıtlardan biri olması muhtemeldir. Geminin postalarının en azından bir kısmının kaplamalardan önce yapıya eklendiğini gösteren başka bir kanıt ise bazı postaların kaplama sıralarını bir araya getiren sokra ve parileler üzerinde konumlandırılmasıdır. Aralarında kenar bağlantısı bulunmayan bu kaplamaların postalar yerine yerleştirilmeden yapıya dâhil edilmesi mümkün görünmemektedir.

\section{Sonuç}

Mevcut verilere göre Yenikapı 27'nin iskeleti ya da iskeletinin bir kısmı yüksek olasılıkla kabuğu oluşturan kaplamalardan önce inşa edilmiştir. Ancak yapım aşamasında iskeletin önce yapılmış olması geminin tamamen iskelet bazlı bir teknikle inşa edildiğini göstermemektedir. Geminin gövde formunu büyük olasılıkla postaların belirlemiş olması, postaların düzenli aralıklarla dizilimi ve döşeklerin omurgaya demir çivilerle sabitlenmesi, istralya, yumru gibi iskeleti uzunlamasına destekleyen

17 Lucien Basch, “Ancient Wrecks and the Archaeology of the Ships," International Journal of Nautical Archaeology 1 (1972), 35-36.

18 Basch, "Ancient Wrecks and the Archaeology of the Ships," 35-36; Richard Steffy, "The Mediterranean Shell to Skeleton Transition: A Northwest European Parallel," Carvel Construction Technique: Skeleton-First, Shell-First. Proceedings 5th International Symposium on Boat and Ship Archaeology, Amsterdam 1988, ed. H. R. Reinders ve K. Paul (Oxford: Oxbow Books, 1991), 1-9; Patrice Pomey, "Principles and Methods of Construction in Ancient Naval Architecture," The Philosophy of Shipbuilding: Conceptual Approaches to the Study of Wooden Ships, ed. Frederick M. Hocker ve Cheryl A. Ward (College Station: Texas A\&M University Press, 2004), 25-36; Fred Hocker, "Shipbuilding: Philosophy, Practice and Research," The Philosophy of Shipbuilding: Conceptual Approaches to the Study of Wooden Ships, ed. F. Hocker ve C. A. Ward (College Station: Texas A\&M University Press, 2004), 1-11. 
elemanların kullanılması, kaplama tahtaları arasında bağlantı olmaması ve sokraların kullanılması gibi özellikler iskelet tekniğine işaret etmektedir. Ancak buna rağmen postaların düzensiz formları, döşek-posta üstü bağlantılarının olmaması ve burma tahtalarının omurgaya bağlı olması geminin yapısal mukavemetinin sağlanmasında ne iskelet ne de kabuk kısmının baskın olmadığını göstermektedir. Buna göre geminin daha çok antik dönemde yaygın olan kabuk-ilk tekniğinden, geminin yapıldığı dönemde yeni gelişmeye başlayan iskelet-ilk tekniğine geçiş dönemini çok iyi yansıtan, her iki tekniğe de özgü bazı geleneklerin inşa süreci sırasında göz ardı edilmediği karma ya da özgün bir anlayışla inşa edildiği tespit edilmiştir.

Hakem Değerlendirmesi: Dış bağımsız.

Çıkar Çatışması: Yazar çıkar çatışması bildirmemiştir.

Finansal Destek: Tez çalışması, 53180 numaralı proje ile İstanbul Üniversitesi Bilimsel Araştırma Projeleri Birimi tarafından desteklenmiştir.

Peer-review: Externally peer-reviewed.

Conflict of Interest: The author has no conflict of interest to declare.

Grant Support: This thesis study is supported by Istanbul University's Scientific Research Projects Unit with the project numbered 53180

\section{Kaynakça/References}

Akkemik, Ünal. Yenikapı Batıkları Cilt II: Yenikapı Batıklarının Ahşapları. İstanbul: Ege Yayınları, 2015.

Algan, Oya, Namık Yalçın, İsak Yılmaz, Elmas Kırcı Elmas, Erol Sarı, Demet Ongan, Özlem Buldan-Yeşiladalı, Doğan Perinçek, Mehmet. Özdoğan, Yücel Yılmaz ve İsmail Karamut. “Antik Theodosius Limanı'nın (Yenikapı) Jeo-Arkeolojisi.” İstanbul Arkeoloji Müzeleri, I. MarmarayMetro Kurtarma Kazıları Sempozyumu Bildiriler Kitabı 5-6 Mayıs 2008. Ed. Ufuk Kocabaş. İstanbul: Epsilon Yayıncılık, 2010, 175-180.

Barkai, Ofra ve Yaacov Kahanov. "The Tantura F Shipwreck, Israel.” International Journal of Nautical Archaeology 36/1 (2007): 21-31.

Basch, Lucien. "Ancient Wrecks and the Archaeology of the Ships.” International Journal of Nautical Archaeology 1 (1972): 1-58.

Hocker, Fred. "Shipbuilding: Philosophy, Practice and Research." The Philosophy of Shipbuilding: Conceptual Approaches to the Study of Wooden Ships. Ed. Frederick M. Hocker ve Cheryl A. Ward. College Station: Texas A\&M University Press, 2004, 1-11.

Kahanov, Yaacov, Jeffrey G. Royal ve Jerome L. Hall. "The Tantura Wrecks and Ancient Mediterranean Shipbuilding." The Philosophy of Shipbuilding: Conceptual Approaches to the Study of Wooden Ships. Ed. Frederick M. Hocker ve Cheryl A. Ward. College Station: Texas A\&M University Press, 2004, 113-127.

Kahanov, Yaacov, Deborah Cvikel, Amir Wielinski ve Eyal Israeli. "Dor Underwater Excavation, Report of the 2008 Season.” Recanati Institute for Maritime Studies News 34 (2008): 16-18.

Kızıltan, Zeynep. "Marmaray-Metro Projeleri Kapsamında Yapılan Yenikapı, Sirkeci ve Üsküdar Kazıları.” İstanbul Arkeoloji Müzeleri, I. Marmaray-Metro Kurtarma Kazıları Sempozyumu Bildiriler Kitabı 5-6 Mayıs 2008. Ed. Ufuk Kocabaş, İstanbul: Epsilon Yayıncılık, 2010, 1-16. 
Kocabaş, Ufuk. "İstanbul Üniversitesi Yenikapı Batıkları Projesi: Gemiler.” İstanbul Arkeoloji Müzeleri, I. Marmaray-Metro Kurtarma Kazıları Sempozyumu Bildiriler Kitabı 5-6 Mayıs 2008. Ed. Ufuk Kocabaş, İstanbul: Epsilon Yayıncılık, 2010, 24-34.

Kocabaş, Ufuk. "The Yenikapı Byzantine-Era Shipwrecks, Istanbul, Turkey: A Preliminary Report and Inventory of the 27 Wrecks Studied by Istanbul University." International Journal of Nautical Archaeology 44/1 (2015): 5-38.

Matthews, Sheila ve Richard Steffy. "The Hull Remains." Serçe Limanı, An Eleventh- Century Shipwreck, Volume 1: The Ship and Its Anchorage, Crew, and Passengers. Ed. George F. Bass, Sheila D. Matthews, J. Richard Steffy ve Frederich H. Van Doorninck Jr. College Station: Texas A\&M University Press, 2004, 81-122.

Mor, Hadas. "The Dor 2001/1 Shipwreck-Hull Construction Report.” Transferts Technologiques en Architecture Navale Méditerraneenne de L'Antiquité aux temps Modernes: Identité Technique et Identité Culturelle. Ed. Patrice Pomey. Paris: Institut Français D'etudes Anatoliennes GeorgesDumezil, 2010, 87-96.

Özsait Kocabaş, Iş11. "The Yenikap1 12 Shipwreck, a 9th-Century Merchantman from the Theodosian Harbour in Istanbul, Turkey: Construction and Reconstruction.” International Journal of Nautical Archaeology 47/2 (2018): 357-390.

Perinçek, Doğan. "Yenikapı Kazı Alanı'nın Son 800 Yıllık Jeo-Arkeolojisi ve Doğal Afetlerin Jeolojik Kesitteki İzleri." İstanbul Arkeoloji Müzeleri, I. Marmaray-Metro Kurtarma Kazıları Sempozyumu Bildiriler Kitabı 5-6 Mayıs 2008. Ed. Ufuk Kocabaş. İstanbul: Epsilon Yayıncılık, 2010, 191-218.

Pomey, Patrice. "Principles and Methods of Construction in Ancient Naval Architecture." The Philosophy of Shipbuilding: Conceptual Approaches to the Study of Wooden Ships. Ed. Frederick M. Hocker ve Cheryl A. Ward. College Station: Texas A\&M University Press, 2004, 25-36.

Pomey, Patrice, Yaacov Kahanov ve Eric Rieth. "Transition from Shell to Skeleton in Ancient Mediterranean Ship-Construction: Analysis, Problems and Future Research." International Journal of Nautical Archaeology 41/2 (2012): 235-314.

Pulak, Cemal, Reca Ingram, Michael Jones ve Sheila Matthews. "The Shipwrecks of Yenikap1 and becTheir Contribution to the Study of Ship Construction." Stories from the Hidden Harbour: Shipwrecks of Yenikapı. Istanbul: Koç Üniversitesi Yayınları, 2013, 22-34.

Pulak, Cemal, Rebecca Ingram ve Michael Jones. "Eight Byzantine Shipwrecks from the Theodosian Harbour Excavations at Yenikap1 in Istanbul, Turkey: an introduction." International Journal of Nautical Archaeology 44/1 (2015): 39-73.

Steffy, Richard. "The Reconstruction of the 11th century Serçe Liman Vessel: A Preliminary Report." International Journal of Nautical Archaeology 11/1 (1982): 13-34.

Steffy, Richard. "The Mediterranean Shell to Skeleton Transition: A Northwest European Parallel." Carvel Construction Technique: Skeleton-First, Shell-First. Proceedings 5th International Symposium on Boat and Ship Archaeology, Amsterdam 1988. Ed. H. Reinder Reinders ve Kees Paul, Oxford: Oxbow Books, 1991, 1-9.

Steffy, Richard. Wooden Shipbuilding and the Interpretation of Shipwrecks. College Station: Texas A\&M University Press, 1994.

Steffy, Richard. "Construction and Analysis of the Vessel." Serçe Limani, An Eleventh- Century Shipwreck, Volume 1: The Ship and Its Anchorage, Crew, and Passengers. Ed. George F. Bass, Sheila D. Matthews, J. Richard Steffy ve Frederich H. Van Doorninck Jr. College Station: Texas A\&M University Press, 2004,153-171.

Türkmenoğlu, Evren. "Yenikap1 27 Batığı: Konstrüksiyon Özellikleri ve Restitüsyon Önerisi." Doktora tezi, İstanbul Üniversitesi, 2017. 